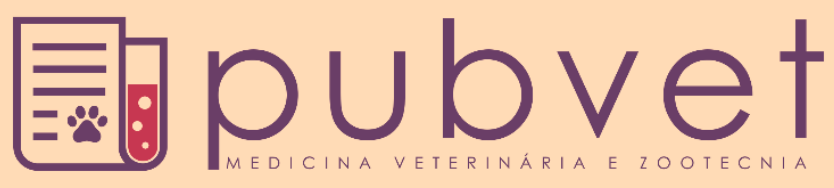

https://doi.org/10.31533/pubvet.v15n09a906.1-6

\title{
Vesiculite unilateral associada com aglutinação espermática: Relato de caso
}

\author{
Marilia de Lima Rezende Reis ${ }^{1}$, Solange Martins Almeida ${ }^{2}$, Neimar Corrêa Severo ${ }^{20}$, Luiz Alfredo \\ Garcia Deragon $^{2 \dagger}$, João Pedro Brandão Zandonaide ${ }^{2} \bullet$, André Belico de Vasconcelos ${ }^{3 *} \bullet$ (D) \\ ${ }^{I}$ Graduada em Medicina Veterinária, Universidade de Uberaba. Uberaba-MG Brasil \\ ${ }^{2}$ Empresa Alta Genetics do Brasil. Uberaba-MG Brasil \\ ${ }^{3}$ Professor da Universidade de Uberaba, Medicina Veterinária. Uberaba-MG Brasil. \\ *Autor para correspondência,E-mail: andre.vasconcelos@uniube.br
}

Resumo. O objetivo deste estudo foi relatar uma condição de aglutinação espermática multifatorial recorrente em um touro da raça Brahman. Mediante estudos microscópicos, microbiológicos e imagem obtida pela ultrassonografia, o animal foi diagnosticado com vesiculite unilateral. Após tratamento com antibiótico a taxa de recuperação foi aproximadamente $90 \%$.

Palavras chave: Andrologia, Bos indicus, Enterococcus spp.

\section{Unilateral vesiculite associated with spermatic agglutination: Case report}

\begin{abstract}
The aim of this study was to report a condition of recurrent multifactorial sperm agglutination in a Brahman bull. Through microscopic, microbiological studies and an image obtained by ultrasound, the animal was diagnosed with unilateral vesiculitis. After antibiotic treatment, the recovery rate was approximately $90 \%$.
\end{abstract}

Keywords: Andrology, Bos indicus, Enterococcus spp

\section{Vesiculitis unilateral asociada a la aglutinación de espermatozoides: Reporte de caso}

Resumen. El objetivo de este estudio fue informar una condición de aglutinación de esperma multifactorial recurrente en un toro Brahman. Mediante estudios microscópicos, microbiológicos y una imagen obtenida por ultrasonido, se diagnosticó al animal de vesiculitis unilateral. Después del tratamiento con antibióticos, la tasa de recuperación fue aproximadamente del $90 \%$.

Palabras clave: Andrología, Bos indicus, Enterococcus spp

\section{Introdução}

Segundo dados da ANUALPEC (2020), Minas Gerais possuía um rebanho bovino de 21,8 milhões de cabeças, das quais 176 mil cabeças pertencem à cidade de Uberaba. Um relatório divulgado no site do Governo do Brasil (2020) a qual o setor agropecuário foi o único que apresentou um crescimento de 1,9\% do Produto Interno Bruto (PIB) neste primeiro trimestre (comparado com os dados do mesmo período do ano passado), de acordo com dados colhidos pelo Instituto Brasileiro de Geografia e Estatística (IBGE) de (Brasil, 2020).

Deste modo, é importante destacar a grande importância da bovinocultura tem para o país. O melhoramento genético é um dos parâmetros que alavancaram este crescimento na pecuária e tem por objetivo trazer características positivas de produção por meio de animais melhoradores (Oliveira et al., 1999). Assim, a condição de melhorador se dá principalmente aos touros nos quais o impacto na reprodução é muito maior, 
desta forma as avalições clínicas andrológicas têm um papel relevante na seleção do animal. Bicudo et al. (2007) e Oliveira et al. (2018) descreveram que animais que possuem maior circunferência escrotal podem desenvolver vesiculite unilateral, pois, atingem a puberdade mais cedo e são mais precoces sexualmente. Uma vez que em algumas condições como lesão peniana e consequentemente uma infecção ascendente pela uretra pode promover esta enfermidade (Oliveira et al., 2018). Tendo em vista que o agente etiológico pode promover a colonização em uma ou ambas as vesículas, caracterizando a vesiculite, mesmo ainda não havendo conhecimento especifico da patogenia (Scheeren, 2019), o que pode promover uma aglutinação espermática.

O objetivo deste relato é apresentar uma condição de aglutinação espermática multifatorial recorrente em um touro da raça Brahman.

\section{Relato do caso}

No início do ano de 2020 foi observado que um touro da raça Brahman, idade aproximadamente quatro anos, a manifestação de um processo espermático denominado aglutinação, com intensificação durante o andamento dos meses. $\mathrm{O}$ animal recebia antes e depois da manifestação da condição espermática uma alimentação balanceada a base de pastagem e uma dieta disponibilizada duas vezes ao dia (18 kg/dia/animal), composta por 34,9\% de silagem de milho, 5,9\% de feno, 17,4\% de polpa cítrica, $5,2 \%$ de farelo de soja, 34,9\% de silagem de sorgo ou capim (depende da época do ano), 1,7\% de núcleo mineral. Totalizando assim o cálculo da dieta em $100 \%$.

Foram realizadas 14 coletas e todas por meio de vagina artificial, devidamente aquecida $\left(37^{\circ} \mathrm{C}\right) \mathrm{e}$ lubrificadas. Após as coletas as amostras foram avaliadas quanto as características físicas de motilidade espermática e vigor espermático e concentração espermática.

Após a observação da manifestação de aglutinação foi realizada anamnese, com o objetivo de indicar alguma característica clínica, que poderia estar associada à condição de aglutinação. Assim foi mensurado o perímetro escrotal tracionando os testículos caudalmente e com auxílio de uma fita métrico posicionada no maior diâmetro escrotal.

Na palpação dos testículos, os dois se apresentavam flácidos e macios, sendo o esquerdo com maior evidencia de flacidez. A cauda do epidídimo de ambos estava aumentada de tamanho. Na palpação retal, notou-se que a próstata e as glândulas vesiculares apresentavam-se rígidas. Porém, somente a glândula vesicular esquerda apresentou um aspecto edemaciada nas extremidades e rígido ao centro, bem com a ampola. Por fim, foi mensurada a temperatura, a qual se apresentava normal, $38,2^{\circ} \mathrm{C}$.

Juntamente a anamnese foi realizado um exame complementar ultrassonográfico transretal das glândulas acessórias, com auxílio de um transdutor linear lubrificado com gel próprio. A imagem obtida da glândula vesicular esquerda observou-se um contorno um pouco irregular, com membrana que circunda toda glândula, hiperecóica, porém, levemente espessa e pouco homogênea (setas verdes). Não aparente os lóbulos glandulares característicos do órgão e sim uma presença de área hipoecóica com um aspecto desuniforme ao centro (seta vermelha) (Figura 1).

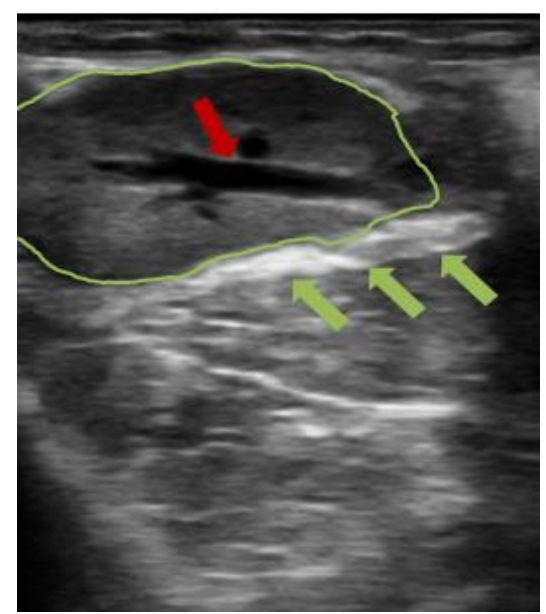

Figura 1. Ultrassonografia da glândula vesícula seminal esquerda, do touro da raça Brahman. 
Após essas alterações notadas na ultrassonografia, juntamente com a persistência da aglutinação, uma partida do sêmen foi coletada e identificada com a finalidade de ser encaminhado ao laboratório, para teste de sensibilidade a antimicrobianos (TSA) e para espermocultura. Também foi avaliado o processo de aglutinação, teste este realizado com o anticorpo anti-esperma, como método de descarte diagnóstico. Para tal teste foi feito a coleta sanguínea em um tubo com citrato de sódio e, posteriormente, adicionou-se em uma lâmina 8 microlitros do sangue e ao lado 8 microlitros do sêmen fresco com diluente, com a ponteira homogeneizou-se e colocou-se uma lamínula para observação em microscópio óptico no aumento de 20X e de 1000X.

Após os resultados acima descritos, o animal foi tratado com administração de duas doses de $30 \mathrm{~mL}$ de Draxxin ${ }^{\circledR}$, com um intervalo entre elas de seis dias.

\section{Discussão}

ABCZ (2014) e Freire et al. (2001), como também Rosa et al. (2016), apontaram que os reprodutores são os maiores responsáveis por agregar valor ao desenvolvimento genético. Um touro garante cerca de $84 \%$ a $88 \%$ do ganho genético do rebanho; além disso, destacam que, enquanto a matriz deixa até 10 proles, o touro melhorado pode ser pai de dezenas, isso em monta natural, mas este número pode ser muito maior quando utilizado a comercialização de sêmen congelado. Assim a seleção e avaliação do potencial reprodutivo dos touros, como: idade, qualidade do sêmen, circunferência escrotal, libido, puberdade, precocidade são características reprodutivas de extrema importância levando em consideração os programas de melhoramento genético (Costa e Silva, 1994; Crudeli, 1990).

Das avaliações microscópica do sêmen quanto a motilidade e vigor os valores médios foram de $42,4 \%$ e 3,2, respetivamente, com a concentração espermática média de $655,6 \mathrm{sptz} / \mathrm{cm}^{3}$. Conforme o definido pelo Colégio Brasileiro de Reprodução Animal - CBRA (2013), a motilidade espermática deve ser $\geq 50 \%$ e vigor $\leq 3$ valores limítrofe ao definido, quanto a concentração está dentro do definido pelo CBRA.

Quanto a mensuração do perímetro escrotal foi obtida um valor de $37 \mathrm{~cm}$, valor este semelhante aos descritos por Fonseca et al. (2019) e Pineda et al. (2000) com valor médio 36,8 $\pm 2,7 \mathrm{~cm}$.

A presença de patógenos pode promover ao animal alterações significativas nos exames andrológicos (valores inferiores ao de referência para motilidade e vigor), sem apresentar sinais clínicos evidentes, para tal situação (Oliveira et al. 2018).

O resultado do teste de aglutinação com o anticorpo anti-esperma, foi caracterizado como não específicos. No teste de sensibilidade a antimicrobianos (TSA) e para espermocultura, apresentou resultados que apontaram a presença de Enterococcus spp.

A aglutinação espermática é definida como um fenômeno causado por espermatozoides móveis que se aderem entre si por cabeça, cauda ou peça intermediária, em situação contrária é denominado agregação (Arruda et al., 2011; Freneau, 2011; Valdebenito et al., 2009). A causa deste fenômeno não é muito bem elucidada pela literatura, com explicações variadas. Alguns trabalhos atribuem esse achado à alteração do potencial elétrico da membrana espermática (Cunha \& Lopes, 2009), outros a componentes da gema do ovo utilizados nos diluidores (Yang et al., 2012) e outros ainda a anticorpo antiespermatozoide (Rocha, 2005) ou a causas bacterianas (Batista et al., 2012).

Mediante aos resultados observados acredita-se que a aglutinação espermática manifestada pelo touro no presente relato possa ter sido desenvolvida e persistida até certo tempo por uma associação de motivos. Contudo inicialmente o animal pode ter desenvolvido uma vesiculite, denominado como um processo inflamatório das glândulas vesiculares.

O diagnóstico de vesiculite foi confirmado por dois exames: primeiro pelo exame de palpação, no qual se observou achados semelhantes deste caso com os encontrados por Oliveira et al. (2018) e Bicudo et al. (2007), que relataram encontrar glândulas vesiculares aumentadas de tamanho, consistente à palpação retal e frequentemente com presença de um tecido fibrótico além da perda na arquitetura lobular da glândula por aumento de tamanho e que em alguns casos mais severos pode-se encontrar uma maior consistência.

O segundo pelo exame de ultrassonografia, com resultados semelhantes aos descritos por Oliveira et al. (2018) (Figura 2). 

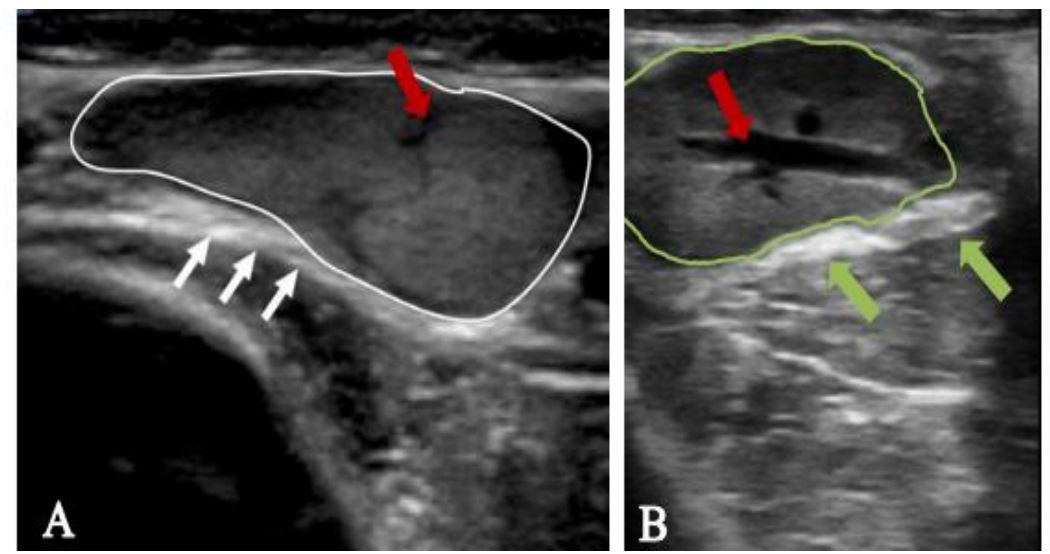

Figura 2. Imagem ultrassonográfica comparativa de glândula vesicular normal e patológica. (A) glândula vesicular normal (contorno branco), com superfície regular, presença de lóbulos glandulares com áreas hipoecóica entre si (seta vermelha) e existência de uma membrana hiperecóica e homogênea que circunda toda glândula (setas brancas). (B) glândula vesicular patológica do touro da raça Brahman, Uberaba, 2020 (contorno verde), parede com contorno um pouco irregular, membrana que circunda toda glândula, hiperecóica; porém, levemente espessa e pouco homogênea (setas verdes). Não aparente os lóbulos glandulares característicos do órgão e sim uma presença de área hipoecóica com um aspecto desuniforme ao centro (seta vermelha).

Conforme o resultado de sensibilidade a antimicrobianos (TSA) o animal foi tratado o esquema do tratamento realizado no animal para o presente relato baseou-se no descrito por Bianchin \& Honer, 1995) uma vez que o agente antimicrobiano tem ação bacteriostática e com princípio ativo a Tulatromicina, além do medicamento apresentar características de amplo espectro, conforme o resultado do TSa. De acordo com Rovay et al. (2008), a eficiência da Tulatromicina seria relacionada a liberação lenta nos sítios de infecção, uma vez que o princípio ativo se acumula nos macrófagos e neutrófilos e que estas células de defesa transportariam de forma mais eficiente. Além disso, afirmaram também que além de este princípio ativo possuir uma taxa de recuperação de $88 \%$, possuía uma cobertura que dura seis dias, com apenas um único tratamento, fato que se assemelha ao tratamento realizado no animal de nosso estudo, porém diferentemente se utilizou aqui uma dose reforçada. Após algumas semanas o animal não apresentou mais a aglutinação espermática, identificando-se além disto uma melhora significativa na motilidade (75\%); vigor (5), concentração de 808 espermatozoides $/ \mathrm{cm}^{3}$.

\section{Conclusão}

Após o entendimento de todas as supostas causas da aglutinação espermáticas e levando em consideração a bactéria isolada na espermocultura, a aglutinação observada (a qual persistia até a administração do antibiótico), o exame andrológico os achados da anamnese geral durante a palpação retal e a ultrassonografia, constatou-se ser um caso de vesiculite unilateral, associada com uma aglutinação multifatorial. Vale destacar que para o fechamento do diagnóstico os testes e exames microbiológicos, microscópicos e de imagens complementares foram ferramentas imprescindíveis. Este diagnóstico permitiu a realização do tratamento adequado que se mostrou eficiente e eficaz com a reversão do problema. Além disto, este estudo de caso fornece um alerta quanto a importância de um diagnóstico correto orientando um tratamento eficaz e eficiente altamente necessário para o melhoramento dos animais reprodutores.

\section{Agradecimento}

In memoriam a Luiz Alfredo Garcia Deragon, Médico Veterinário pesquisador pela contribuição no desenvolvimento da pecuária Brasileira.

\section{Referências}

ABCZ. (2014). Programa de Melhoramento Genético de Zebuínos. Controle de Desenvolvimento Ponderal (Vol. 1). Associação Brasileira de Criadores de Zebu.

ANUALPEC. (2020). Anuário da Pecuária Brasileira (20th ed., Vol. 1). Instituto FNP. 
Arruda, R. P., Celeghini, E. C., Alonso, M. A., Carvalho, H. F., Oliveira, L. Z., Nascimento, J., Silva, D. F., Affonso, F. J., Lemes, K. M., \& Jaimes, J. D. (2011). Métodos de avaliação da morfologia e função espermática: momento atual e desafios futuros. Revista Brasileira de Reprodução Animal, $35(2), 145-151$.

Batista, F., Ramos, G., Wildemann, P., Neto, A. T., Ferraz, S. M., \& Vaz, E. K. (2012). Influência da contaminação bacteriana sobre os parâmetros espermáticos de suínos e perfil de resistência dos agentes isolados. Archives of Veterinary Science, 17(4), 27-33. https://doi.org/10.5380/avs.v17i4.25804.

Bianchin, I., \& Honer, M. R. (1995). Verminose bovina: ocorrencia e controle estrategico. In Embrapa Gado de Corte-Séries Anteriores. Campo Grande: EMBRAPA-CNPGC, 1995.

Bicudo, S. D., Siqueira, J. B., \& Meira, C. (2007). Patologias do sistema reprodutor de touros. Biológico, 69(2), 43-48.

Brasil (2020). Governo do Brasil. MAPA (org.). Agropecuária cresce 1,9\% no primeiro trimestre, diz IBGE. Disponível em: https://www.gov.br/pt-br/noticias/agricultura-epecuaria/2020/06/agropecuaria-cresce-1-9-no-primeiro-trimestre-diz-ibge.

CBRA - Colégio Brasileiro de Reprodução Animal. (2013). Manual para exame andrológico e avaliação de sêmen animal (3 ed.) CBRA, Belo Horizonte, Brasil.

Costa e Silva, V. E. (1994). Avaliação da capacidade reprodutiva de touros Nelore. Exame andrológico, teste de comportamento sexual e desafio da fertilidade. In Escola de Veterinária: Vol. Master of. Universidade Federal de Minas Gerais.

Crudeli, G. A. (1990). Avaliação da aptidão reprodutiva de touros de raça Nelore e seu efeito sobre a taxa de gestação do rebanho. In Escola de Veterinária: Vol. Master of. Universidade Federal de Minas Gerais.

Cunha, I. C. N., \& Lopes, M. D. (2009). Effect of centrifugation on quality of canine semen. Arquivo Brasileiro de Medicina Veterinária e Zootecnia, 61(1), 104-109.

FAPRI. (2020). Food and Agricultural Policy Research Institute. Food and Agricultural Policy Research Institute; Iowa State University and University of Missouri-Columbia.

Fonseca, V. O., Souza, C. F., Azevedo, N. A., Oliveira, L. Z., Monteiro, G. A., Cavalcanti, L. F. L., \& Molina, L. R. (2019). Parâmetros reprodutivos de touros Nelore (Bos taurus indicus) criados a pasto, em de diferentes faixas etárias. Arquivo Brasileiro de Medicina Veterinária e Zootecnia, 71, 385-392.

Freire, E. C., Lima, E. F., Adrade, F. P., Milani, M., \& Nóbrega, M. B. (2001). Melhoramento genético. O Agronegócio Da Mamona No Brasil, 2, 169-194.

Freneau, G. E. (2011). Aspectos da morfologia espermática em touros. Revista Brasileira de Reprodução Animal, 35(2), 160-170.

IBGE (2018). SIDRA (org.). Tabela dos rebanhos por tipo de rebanhos. Disponível em: https://sidra.ibge.gov.br/tabela/3939\#resultado.

Oliveira, R. G. A., Silva, L. O. C., Euclides Filho, K., \& Figueiredo, G. R. (1999). Dissemination of genetic improvement in beef cattle. Disseminação Do Melhoramento Genético Em Bovinos de Corte, 28(6), 1219-1225. http://www.scopus.com/inward/record.url?eid=2-s2.00347786494\&partnerID=40\&md5=c1435cec72d5b2fbf1 ba03ebe46d671f

Oliveira, R. P. L., Favaro, P. C., Pereira, G. R., Barca, F. A., Borges, M. H. F., Galdioli, V. H. G., \& Koetz, C. (2018). Ultrassonografia no auxílio do diagnóstico de vesiculite seminal em touros de corte. Pesquisa Veterinária Brasileira, 38, 1038-1042. https://doi.org/10.1590/1678-5150-pvb-5414.

OMS - Organização Mundial da Saúde (2018). Manual de laboratório da OMS: exame e processamento do sêmen humano (5 ed., p. 17). OMS, Rio de Janeiro, Brasil.

Pineda, N. R., Fonseca, V. O., \& Proença, R. V. (2000). Potencial reprodutivo de touros Nelore: libido, capacidade de serviço e eficiência em acasalamentos com elevada proporção de vacas. Revista Brasileira de Reprodução Animal, 24(1), 44-50.

Rocha, F. B. M. (2005). Evolução e perfil dos anticorpos antiespermatozóides nos primeiros 180 dias em indivíduos vasectomizados. Repositório Institucional, 96, 22-31. 
Rosa, A. N., Torres Júnior, R. A. A., Costa, F. P., Menezes, G. R. O., \& Nogueira, E. (2016). Potencial de retorno econômico pelo uso de touros Nelore geneticamente superiores em monta natural. Embrapa Gado de Corte-Documentos, 1, 1-16.

Rovay, H., Barth, A. D., Chirino-Trejo, M., \& Martinez, M. F. (2008). Update on treatment of vesiculitis in bulls. Theriogenology, 70(3), 495-503.

Scheeren, V. F. da C. (2019). Vesiculite seminal em garanhões: diagnóstico, evolução e tratamento com substância cauterizante. Repositório Institucional UNESP, 6-14. https://doi.org/11449/180834.

Valdebenito, I., Fletcher, C., Vera, V., \& Fernández, J. (2009). Factores fisicoquímicos que regulan la motilidad espermática en peces: aspectos básicos y aplicados. Una revisión. Archivos de Medicina Veterinaria, 41(2), 97-106.

Yang, D. H., McMillan, A. G., Standley, N. T., Shannon, P., \& Xu, Z. Z. (2012). Extracellular calcium is involved in egg yolk-induced head-to-head agglutination of bull sperm. Theriogenology, 78(7), 1476-1486. https://doi.org/10.1016/j.theriogenology.2012.06.021.

Histórico do artigo:

Recebido: 17 de abril de 2021

Aprovado: 30 de maio de 2021
Licenciamento: Este artigo é publicado na modalidade Acesso Aberto sob a licença Creative Commons Atribuição 4.0 (CC-BY 4.0), a qual permite uso irrestrito, distribuição, reprodução em qualquer meio, desde que o autor e a fonte sejam devidamente creditados. 